\title{
O OBELISCO DE PELOTAS E SUA ANÁLISE ICONOGRÁFICA
}

\section{THE OBELISK OF PELOTAS AND ITS ICONOGRAPHIC ANALISIS}

Laura Giordani ${ }^{1}$

Resumo: Na cidade de Pelotas, no estado do Rio Grande do Sul, no bairro Areal, há um monumento erguido no século XIX em prol do ideal republicano. O Obelisco Republicano - ou Obelisco Domingos José de Almeida ou Monumento Republicano - foi inaugurado em 7 de Abril de 1885, homenageando Domingos José de Almeida, político e investidor que residiu em Pelotas, e a República Rio-Grandense, que existiu durante a Guerra dos Farrapos (1835-1845). Essa coluna é o único monumento de cunho republicano erguido no Brasil durante o governo monárquico. O objetivo desse artigo é analisar os elementos presentes em sua estrutura - símbolos, datas, localização, formato e placas - para interpretar que mensagem dos idealizadores do monumento buscavam mostrar a respeito de Domingos de Almeida e o republicanismo.

Palavras-Chave: Obelisco; Pelotas; Republicanismo; Domingos de Almeida; Monumento.

Abstract: In the city of Pelotas, in the state of Rio Grande do Sul, in the Areal district, there is a monument erecter during the nineteenth century in favor of the republican ideal. The Republican Obelisk - or Obelisk Domingos José de Almeida or Republican Monument - was inaugurated April 7, 1885 honoring Domingos José de Almeida, a politician and investor who resided in Pelotas, and the Riograndense Republic, which existed during the Ragamuffin War (1835 - 1845). This column is the only republican monument erected in Brazil during the monarchial government. The aim of this paper is analyze the elements present in its structure - symbols, dates, location, format and plates - to interpret

\footnotetext{
${ }^{1}$ Graduanda do curso de Bacharelado em História pela Universidade Federal de Pelotas (UFPel).
} 
what message it's creators sought to show about Domingos de Almeida and the republicanism.

Key Words: Obelisk; Pelotas; Republicanism; Domingos de Almeida; Monument.

No último quartel do século XIX, a monarquia brasileira começou a se tornar impopular e perder apoiadores políticos, que começaram a simpatizar com o modelo de governo Republicano. Esse modo de governo começou a ser visto por jovens políticos e por alguns setores do Partido Liberal como ideal para o desenvolvimento do país, ao contrário da Monarquia que, segundo esses dois grupos, estava atrasando o progresso do Brasil para o mundo moderno.

Movimentos republicanos do passado começaram a ser relembrados em caráter regional - tais como a Inconfidência Mineira e a Confederação do Equador - para reforçar o ideal republicano dos partidos que surgiam (PACHECO, 2006, p.140). No Rio Grande do Sul, a Revolução Farroupilha e a República Rio-Grandense foram usadas no discurso do Partido Republicano Rio-Grandense (PRR) como exemplo de progresso e autonomia, assim como de bravura perante o que eles consideravam como a tirania da monarquia e seu centralismo. O republicanismo formulado pelo PRR saudava os ideais do republicanismo farroupilha junto com o ideal positivista de Auguste Comte.

Esse modelo de republicanismo foi adotado pelos variados partidos e clubes republicanos que surgiram por todo o estado do Rio Grande do Sul no mesmo período, sendo um deles o Partido Republicano de 
Pelotas, cuja contribuição mais visível foi a construção do Obelisco Republicano, localizado nos arredores da cidade de Pelotas.

\section{Partido Republicano de Pelotas e a Construção do Obelisco}

O Partido Republicano de Pelotas foi organizado em fevereiro de 1881, tendo jovens da elite local como membros. O partido declarava que sua fundação era um modo de preparar Pelotas e a província para um futuro próximo, no qual a República seria o sistema de governo no Brasil (OSÓRIO, 1997: p. 218), tendo candidatos para cargos políticos municipais e locais.

Por conta da sua disposição em erguer um monumento em prol do republicanismo, é possível que, apesar de acreditarem que o fim da monarquia estava próximo, a República tomaria seu lugar natural como sistema de governo e uma nova geração de políticos assumiria a direção do país. Por isso, era necessário que o ideal republicano tivesse um marco físico.

A ideia de um monumento em prol ao ideal republicano já havia sido levantada pelo jornal pelotense A Discussão, em 1881, utilizando a imagem de Tiradentes. A sugestão parece ter agradado os membros do Partido Republicano de Pelotas, pois eles votaram e aprovaram, em setembro de 1884, a construção de um monumento em homenagem ao republicanismo. A comissão que elaborou o projeto estava sob o comando de Álvaro José Gonçalves Chaves, um dos organizadores do partido, e foi decidido que o monumento teria Domingos José de Almeida como homenageado, no lugar de Tiradentes. O motivo para essa 
troca provavelmente tenha sido o resgate da lembrança da Revolução Farroupilha e da República Rio Grandense, que, como foi dito anteriormente, estava sendo vista como modelo pelos republicanos gaúchos. Assim, para os idealizadores do monumento, era mais adequado um homenageado ligado à história rio-grandense e não um herói de Minas Gerais.

A inauguração do Obelisco ocorreu no dia 7 de abril de 1885 , que coincidiu com a data de abdicação de D. Pedro I ao trono e com o ano do cinquentenário do início da Revolução Farroupilha. A data possivelmente foi uma espécie de provocação por parte dos republicanos, pois demonstra como eles comemoravam a ausência do primeiro imperador ao erguerem um monumento republicano no aniversário do ocorrido. Portando, há um valor simbólico na data.

Adicionado a isso, por ter sido inaugurado quatro anos antes da proclamação da República Brasileira, o Obelisco Republicano de Pelotas é o único monumento no Brasil de natureza republicana erguido durante o Período Monárquico.

A coluna tinha como propósito servir de inspiração e de lembrança a toda uma geração de políticos sobre o exemplo de um "digno patriota" ao perpetuar a memória de Almeida, um republicano.

\section{O republicano Domingos José de Almeida}

A Revolução Farroupilha não foi feita apenas com homens armados no campo de batalha. Por também ter sido um movimento com cunho político, homens como Domingos José de Almeida foram necessá- 
rios para que a revolta civil pudesse se consolidar em um governo republicano.

Nascido em uma pequena cidade em Minas Gerais, Domingos José de Almeida chegou na província de São Pedro do Rio Grande do Sul em 1819 e se instalou na freguesia de São Francisco de Paula, atual cidade de Pelotas. Autodidata em economia, política e direito, ele diversificou seus empreendimentos no setor industrial, sendo que foi a indústria do charque que trouxe mais lucro.

Almeida teve uma vida política agitada, sendo eleito para a Câmara Municipal da então Vila de São Francisco de Paula, servindo o mesmo cargo quando a vila foi elevada a município com o nome de "Pelotas" em 1835, e agindo como deputado na Assembleia Provincial. A historiadora Ilka Neves descreve a atuação de Almeida, segundo a análise das atas da câmara municipal, como "interessante e inovadora" (NEVES, 1987: p.16).

Quando a Revolução Farroupilha estourou em 1835, Domingos José de Almeida se posicionou imediatamente a favor dos rebeldes e começou a trabalhar em serviço da causa, apesar de possuir o cargo de Major na Guarda Nacional, através de atuações políticas e econômicos, o que fez os historiadores unânimes em caracterizá-lo como "o cérebro pensante da revolução". Quando a República Rio-Grandense foi declarada em 1836, Domingos de Almeida foi um dos organizadores da nova República, sendo esse um de seus atos mais marcantes. Durante a breve duração da República, Almeida atuou em diversos cargos - Ministro do Interior e da Fazenda, Ministro da Justiça, Vice-Presidente da Repúbli- 
ca, General Quartel-Mestre, participou da Assembleia Constituinte como deputado e foi um dos redatores da constituição Rio-Grandense -, sendo seu primeiro, e principal, cargo o de Ministro do Interior e da Fazenda, em 1836.

Com o término do conflito, Domingos José de Almeida retornou a Pelotas, onde retomou os seus negócios e voltou a trabalhar em prol da comunidade local reassumindo seu cargo de vereador, que cumpriu até 1864, exercendo o cargo de Juiz de Órfãos, e fazendo de atos de filantropia (NEVES, 1987, p. 18). Ele também voltou a compor a Guarda Nacional, dessa vez como Coronel, mas nunca mais retornou à Assembleia Provincial.

Domingos José de Almeida veio a falecer em sua residência, na cidade de Pelotas, no dia 6 de maio de 1871, consequência dos ataques epiléticos que sofria desde 1859 (MAGALHÃES, 1993: p. 128).

\section{Estrutura e Análise iconográfica}

O Obelisco Republicano possui quase nove metros de altura e aproximadamente dois de base, sua estrutura toda é feita em alvenaria. Nas suas quatro faces estão distribuídos onze elementos, todos ao alcance dos olhos: duas placas de bronze, três símbolos em argamassa e seis datas em massa de cimento. 
Cadernos de Clio, Curitiba, v. 6, nº. 2, 2015

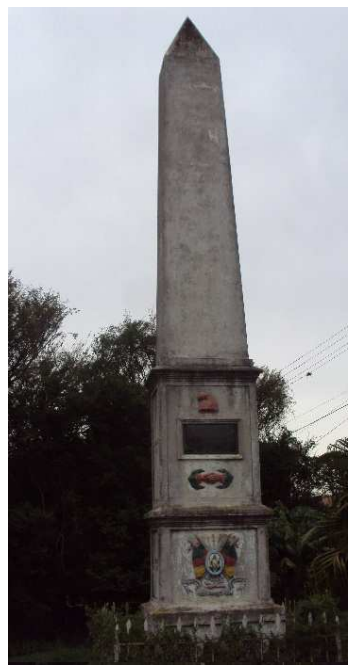

Obelisco Republicano, Bairro Areal em Pelotas - RS

(Fotografias da autora)

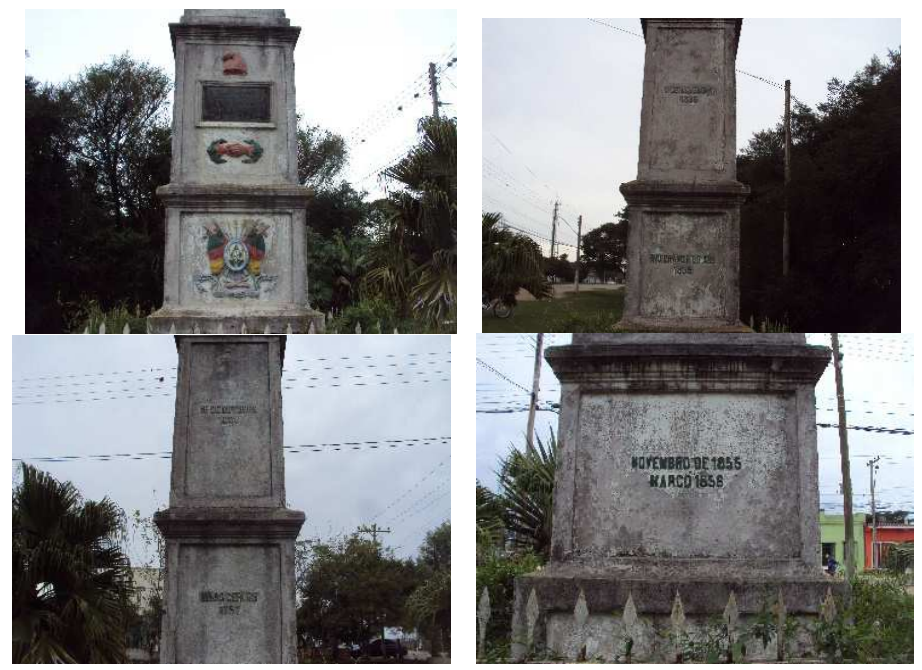

$\mathrm{Na}$ ordem, Face Frontal, Face Direita, Face Esquerda e Face Posterior do Obelisco

(Fotografias da autora) 
É interessante notar que o Obelisco Domingos de Almeida foi erguido em um local afastado do centro da cidade, estando localizado no bairro Areal, a uma distância considerável do centro da cidade e um local de pouca circulação de pedestres, principalmente na época de sua inauguração. Adicionado a isso, em sua estrutura, não há nenhum tipo de representação da imagem de Almeida.

A localização do Obelisco é simbólica, o local onde ele foi erguido é o mesmo lugar onde funcionou a charqueada de Almeida, marcando o local onde ele viveu e morreu em Pelotas. A região já havia se beneficiado com os investimentos na indústria que Almeida havia feito durante seus anos de vida, um monumento em sua homenagem naquele local era visto como indispensável. Hoje, a avenida que se estende pelo bairro Areal e passa em frente ao Obelisco leva o nome de Almeida.

Ao que tudo indica, o monumento segue a vertente Napoleônica da Estatuamania Francesa, onde o obelisco é utilizado como marco e indicador de locais de importância. Nessa vertente de construção de monumentos, se exclui a forma humana do homenageado, valorizando seus atos e méritos, não a sua imagem como indivíduo (KNAUSS, 2003: p. 178).

O Obelisco também possui uma simbologia de perpetuação de memória. Por sua associação com o deus do sol egípcio e as escrituras hieroglíficas em sua estrutura, no antigo Egito, quem tivesse um obelisco em sua homenagem teria seu nome e sua existência gravado na memória e na história coletiva (SARAIVA, 2007: p. 25). Dedicar um obe- 
lisco a Domingos José de Almeida teve como objetivo imortalizar sua memória e seus atos, tornando-o um exemplo e objeto de admiração.

\section{Face Frontal do Obelisco}

A primeira face do obelisco possui cinco elementos, que serão apresentados aqui do topo para baixo.

O primeiro símbolo é um barrete vermelho moldado em massa de cimento

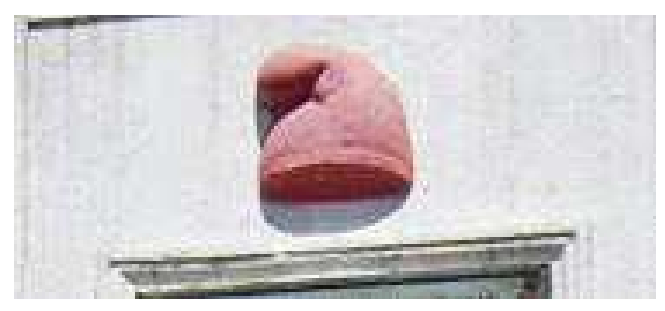

Barrete vermelho, face frontal do obelisco

(Fonte: http://www.vivaocharque.com.br/cenarios/obelisco.php Acessado em 11 de junho de 2013.)

O Barrete Frígio, ou Barrete da Liberdade, é tido como símbolo de uma nova República desde a Revolução Francesa (HUNT, 2007: p. 83), também estando presente na bandeira da República Rio-Grandense e na atual bandeira do estado do Rio Grande do Sul. Como o Obelisco Republicano não remete apenas à Domingos José de Almeida, ele se refere ao homem que organizou a República Rio-Grandense e a República em si, a presença do barrete servia para honrar a República que havia se instaurado e se extinguido há mais ou menos cinquenta anos seguindo a data da inauguração do monumento - como modo de mostrar que ela não havia sido esquecida com o passar do tempo. 
O segundo é uma placa de bronze:

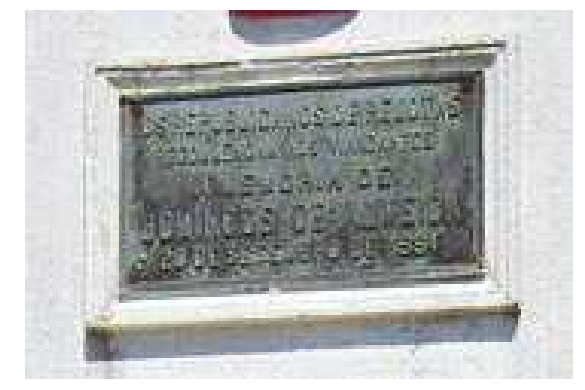

Placa em bronze, face frontal do Obelisco

(Fonte: http://www.vivaocharque.com.br/cenarios/obelisco.php Acessado em 11 de junho de 2013.)

Na placa está escrito:

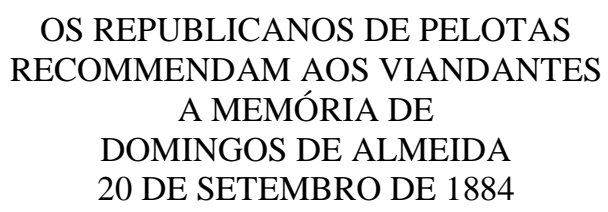

Essa placa é o ponto chave do Obelisco. Nela se informa o nome do homenageado que foi honrado pelo monumento e aponta quem foram os responsáveis pela construção da coluna. Apesar de não se referir diretamente ao Partido Republicano ou à natureza política de Almeida, ela informa que Domingos José de Lameira atraiu a atenção dos simpatizantes desse sistema de governo ao ponto de ter um monumento erguido em sua homenagem.

Nota-se que o nome de Almeida é o único citado especificamente na placa, não se referindo a nenhum outro em particular. $\mathrm{O}$ obelisco como monumento serve como perpetuador da memória e os atos de um 
homem, portanto, tendo apenas o nome de Almeida é um sinal de que a coluna serve apenas de homenagem a ele, sendo o nome de seus construtores irrelevantes para o significado do monumento

A data usada na placa, 20 de setembro de 1884, é o dia em que o Partido Republicano de Pelotas se reuniu para votar a construção da coluna, não o dia em que o monumento foi inaugurado, 7 de abril de 1885. Uma escolha incomum, porém pode ter sido feita por 20 de setembro ser o aniversário da Revolução Farroupilha, conflito o qual os republicanos pelotenses também homenageavam no monumento.

Abaixo da placa, há o terceiro símbolo, um aperto de mãos em massa de cimento pintado em vermelho e verde.

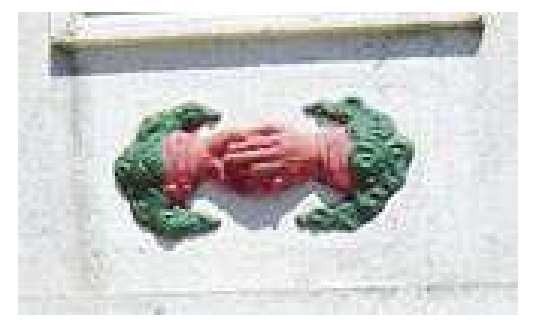

Aperto de Mãos, face frontal do Obelisco

(Fonte: http://www.vivaocharque.com.br/cenarios/obelisco.php Acessado em 11 de junho de 2013.)

Na cultura Ocidental, o aperto de mãos é usado como cumprimento ou uma saudação, que também pode ser empregado para oficializar um acordo informal ou verbal, até mesmo consolidar um contrato formal. Trata-se de uma cordialidade que pode remeter a um sentimento positivo de amizade e confiança. Quando um aperto de mãos é representado sendo feito com a mão esquerda, tal no monumento, segundo dicionários de símbolos, ele representa a Fraternidade. 
Buscando os significados de "Fraternidade" no dicionário, um deles remete a união ou convivência entre irmãos. Trazendo para os contextos da Revolução Farroupilha e do Republicanismo que se formava no fim do século XIX, a busca de um Estado Republicano Federativo, no qual cada estado seria responsável pelo seu território e trabalharia em conjunto com os demais para a grandeza da nação, chega-se à ideia de um trabalho em conjunto, de união.

Outro significado pode ser encontrado na Revolução Francesa, o qual os Farrapos se inspiraram. O lema da Revolução Francesa, "Liberdade, Igualdade e Fraternidade", está, de certa forma, materializado no Obelisco: o próprio Obelisco se referindo à República, como símbolo de igualdade; a liberdade com o barrete frígio; e a fraternidade com o aperto de mãos.

O quarto símbolo do Obelisco é o Brasão de Armas da República Rio-Grandense, moldado em massa de cimento e pintado com as cores oficiais. É a maior peça presente e recebe bastante destaque na face frontal.

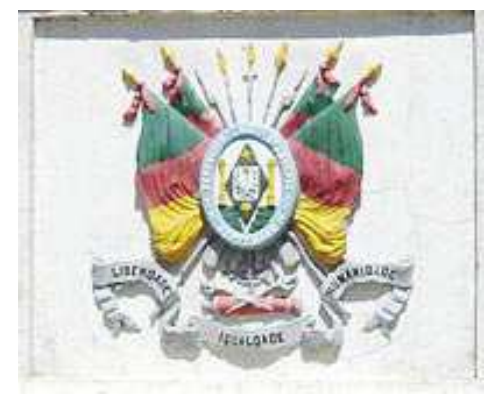

Brasão de Armas Rio-Grandense, face frontal do Obelisco (Fonte: http://www.vivaocharque.com.br/cenarios/obelisco.php Acessado em 11 de junho de 2013.) 
O Obelisco homenageia apenas a Domingos José de Almeida, ele também é um tributo à Revolução Farroupilha e a República RioGrandense. A presença desse brasão é indispensável em um monumento que lembra a República sulina.

O último item na face frontal é uma segunda placa em bronze, que não se encontra mais no Obelisco, pois foi roubada.

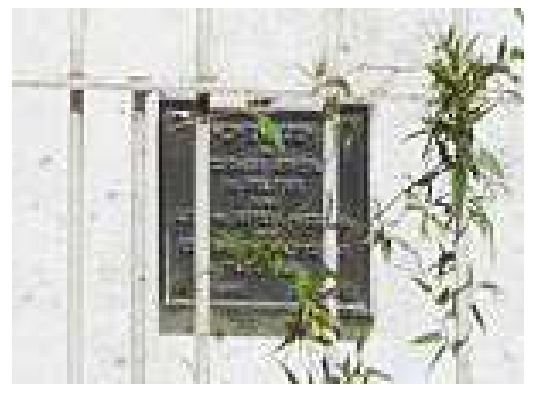

Segunda placa de bronze, face frontal do Obelisco (Fonte: http://www.vivaocharque.com.br/cenarios/obelisco.php Acessado em 11 de junho de 2013.)

Nessa placa, estava escrito:

\author{
HOMENAGEM \\ DA SOCIEDADE AGRÍCOLA \\ DE PELOTAS \\ E DA \\ LIGA DE DEFEZA NACIONAL, \\ NO CENTENÁRIO DA PACIFICAÇÃO \\ FARROUPILHA \\ 3-3-1845 3-3-1945
}

A colocação da placa no monumento é posterior, dadas as datas escritas no bronze. De certa forma, ela se encaixa ao mesmo tempo que 
parece estranha no Obelisco, pois é uma pequena homenagem ao fim da Revolução Farroupilha, algo que os republicanos rio-grandenses consideravam uma derrota. Essa placa parece fora de contexto no conjunto de elementos que formam o Obelisco se considerarmos as intenções de lembrança da experiência republicana no Rio Grande do Sul. A placa foi instalada, segundo a data resignada, em 1945, por ocasião do centenário do fim da Revolução Farroupilha, momento em que o fato histórico gaúcho era mais relevante do que o republicanismo que o Obelisco se dedicava a lembrar.

\section{Face Direita do Obelisco}

A face direita do Obelisco possui duas datas moldadas em massa de cimento e os caracteres pintados em verde.

A primeira registra: 6 de Novembro de 1839

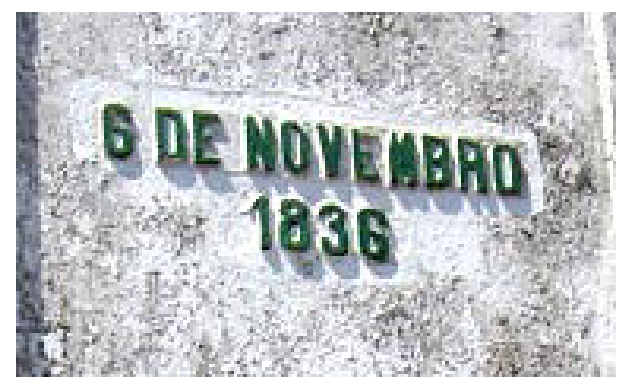

Data na face direita do Obelisco

(Fonte: http://www.vivaocharque.com.br/cenarios/obelisco.php Acessado em 11 de junho de 2013.)

A República Rio-Grandense foi organizada em dois dias - 5 e 6 de Novembro de 1836 -, ato que Domingos José de Almeida participou 
ativamente, sendo que foi no segundo dia que os responsáveis pelos cargos administrativos foram escolhidos. Domingos de Almeida recebeu o Ministério do Interior e da Fazenda, cargo que manteve durante quase toda a existência dessa República.

A segunda data registra: Rio Grande do Sul - 1835

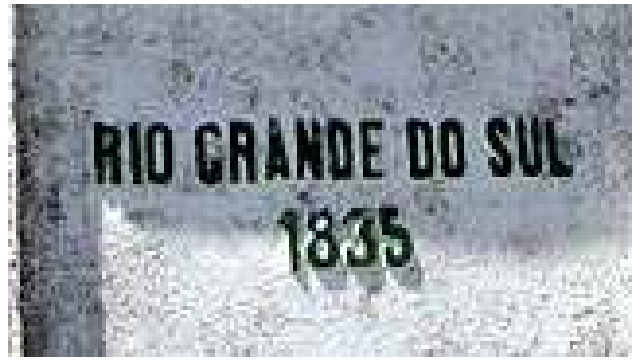

Data na face direita do Obelisco

(Fonte: http://www.vivaocharque.com.br/cenarios/obelisco.php Acessado em 11 de junho de 2013.)

Essa inscrição em cimento refere-se ao ano do início da Revolução Farroupilha, evento que os republicanos gaúchos admiravam por ter marcado um ato, segundo eles, de coragem e enfrentamento à tirania.

\section{Face Esquerda do Obelisco}

$\mathrm{Na}$ face esquerda do monumento há outras duas datas em massa de cimento e pintadas em verde.

A primeira é: 15 de Outubro de 1822 


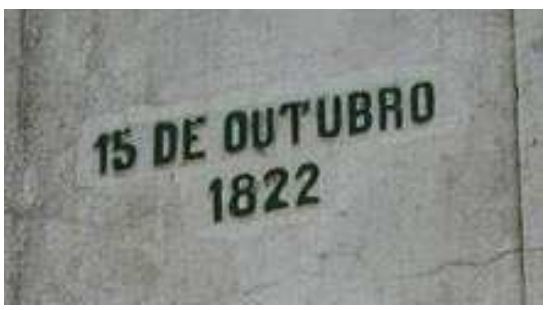

Data na face esquerda do Obelisco

(Fonte: http://www.vivaocharque.com.br/cenarios/obelisco.php

Acessado em 11 de junho de 2013.)

Foi nesse dia a notícia de que o Brasil havia se tornado independente de Portugal chegou em Pelotas. Ao ouvir a notícia, Domingos José de Almeida organizou uma festa para o nascimento de um país livre do colonialismo lusitano. Segundo fontes, ele pagou grande parte do valor da comemoração com o próprio dinheiro.

A segunda data é: Minas Geraes - 1797

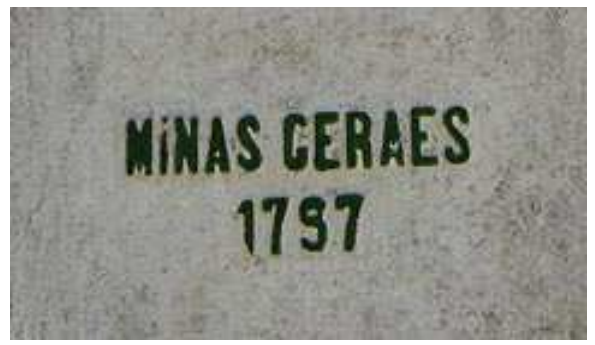

Data na face esquerda do Obelisco

(Fonte: http://www.vivaocharque.com.br/cenarios/obelisco.php

Acessado em 11 de junho de 2013.)

Ano de nascimento de Almeida, em uma pequena cidade na Província de Minas Gerais. Já que o Obelisco foi erguido marcando o local onde ele viveu com sua família e veio a falecer, se torna necessário indicar o ano que ele nasceu e o lugar. 


\section{Face Posterior do Obelisco}

A última face do Obelisco possui duas datas moldadas em massa de cimento e os caracteres pintados com verde: Novembro de 1855 e Março de 1856.

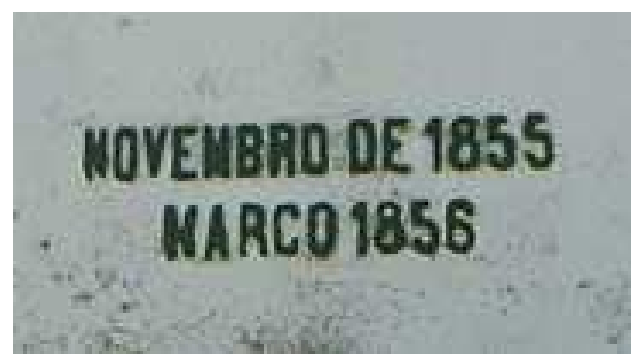

Datas na face posterior do Obelisco

(Fonte: http://www.vivaocharque.com.br/cenarios/obelisco.php

Acessado em 11 de junho de 2013.)

Essas duas datas servem para indicar um dos atos de filantropia praticados por Domingos de Almeida. Em novembro de 1855 os primeiros casos de Cólera Morbus começaram a fazer vítimas em Pelotas. Reagindo à epidemia que se alastrava pela cidade, Almeida financiou a construção de um hospital para tratar das vítimas da doença. O hospital foi fundado em março de 1856.

$\mathrm{O}$ investimento feito por ele foi uma importante obra de caridade para a cidade e os republicanos pelotenses não poderiam deixar esse ato fora de um monumento em homenagem a Almeida, já que o objetivo de erguê-lo era servir de exemplo para futuras gerações. 


\section{Interpretações}

Segundo Alois Riegl, por monumento "compreende-se uma obra de mão humana, construída com o fito determinado de conservar sempre presentes e vivos na consciência das gerações seguintes feitos ou destinos humanos particulares (ou conjuntos de tais feitos e destinos)" (2013, p. 09). Sendo assim, o objetivo de um monumento é preservar um fato ou a memória de um indivíduo do presente ou do passado para que faça parte das memórias de uma nova geração. Na percepção de Álvaro Chaves e dos republicanos de Pelotas, Domingos de Almeida podia ser considerado um cidadão pelotense exemplar, portanto o indivíduo certo para servir de modelo às gerações que viriam posteriormente.

A construção do Obelisco Republicano serviu para demonstrar que uma República era feita por homens de valor, e os republicanos de Pelotas acreditavam que Domingos José de Almeida era exemplo de um homem com essas qualidades. Almeida não pegou em armas pela Revolução Farroupilha e a República Rio-Grandense, ele ajudou a sustentálas utilizando habilidades administrativas e políticas, que eram tão necessárias quanto habilidades militares.

Domingos José de Almeida, ao receber um obelisco como homenagem, teve seus feitos e ideais valorizados, algo que não poderia ser feito caso o monumento tivesse sido projetado para ser uma estátua. Caso a homenagem tivesse sido projetada para ser uma estátua, o monumento acabaria por focar-se na sua imagem, e não no ideal republicano que Almeida defendia. 
Segundo José Murilo de Carvalho "as ideologias republicanas permaneciam enclausuradas no fechado círculo das elites educadas" (CARVALHO, 1990, p. 10), porém em Pelotas, graças a inauguração do Obelisco, esse ideal se fez exposto ao público. Adicionado a isso, ele também apresentava o que seria um suposto exemplo de cidadão republicano. Portanto, a construção do Obelisco Republicano também foi uma forma de educar o cidadão comum, de forma limitada, o que o republicanismo possuía de positivo.

\section{Conclusão}

O Obelisco Republicano, ou Obelisco Domingos José de Almei$d a$, é um monumento único no Brasil. Foi o primeiro monumento erguido com o ideal republicano e o único inaugurado durante o Período Monárquico. E, pelo modo que ele foi planejado, é como se ele não homenageasse apenas a memória de um político de importância local e de uma experiência republicana ocorrida décadas antes. No entendimento de seus idealizadores, o erguimento do Obelisco era uma aposta inovadora no futuro republicano.

$\mathrm{Na}$ incerteza de que sua própria geração conseguiria instaurar a República no Brasil, os simpatizantes desse sistema em Pelotas decidiram erguer um monumento, que relembra a curta existência da República Rio-Grandense e homenageia um indivíduo que defendeu esse ideal, esperando que inspirasse uma nova geração de políticos a seguir esse exemplo. 


\section{Referências Bibliográficas}

CARVALHO, José Murilo. A Formação das Almas: o imaginário da República no Brasil. São Paulo, SP. Companhia das Letras, 1990.

FACHEL, José Plínio Guimarães. Revolução Farroupilha. Pelotas, RS: EGUFPEL, 2002.

FLORES, Moacyr. Revolução Farroupilha. Porto Alegre, RS: Editora Martins Livreiro, 1985.

HARTMANN, Ivar. Aspectos da Guerra dos Farrapos. Novo Hamburgo, RS: Feevale, 2002.

HUNT, Lynn. Formas Simbólicas na Prática Política. In: Política, Cultura e Classe na Revolução Francesa. São Paulo, SP: Companhia das Letras, 2007. Cap. 2

KNAUSS, Paulo. Cidade Panteão: produção social da imaginária urbana. In: KNAUSS, Paulo (coord.) Sorriso da cidade: imagens urbanas e história política de Niterói. Niterói, RJ: Fundação de Arte de Niterói, 2003. Cap. 5.

LESSA, Barbosa. Domingos José de Almeida. Porto Alegre, RS: Tchê! Comunicações, 1985.

NEVES, Ilka. Domingos José de Almeida e sua descendência. Porto Alegre RS: EDIGAL - Editora e Distribuidora Gaúcha Ltda, 1987

OSÓRIO, Fernando. A Cidade de Pelotas. Volume 1. Pelotas, RS: Editora armazém literário, 1997.

PACHECO, Ricardo de Aguiar. Conservadorismo na tradição Liberal: Movimento Republicano (1870-1889). In: BOEIRA, Nelson (coord.); GOLIN, Tau (coord.). História Geral do Rio Grande do Sul. Vol. 2. Passo Fundo, RS: Livraria e Editora Méritos Ltda, 2006. 
RIEGL, Alois. O culto moderno dos monumentos. Lisboa: Edições 70, 2013.

SARAIVA, MÁRCIA Raquel de Brito. Pinduricalhos da Memória: Usos e Abusos dos Obeliscos no Brasil (Séculos XIX, XX e XXI). Dissertação. Porto Alegre, RS: Programa de Pós-Graduação em História das Sociedades Ibéricas e Americanas PUC-RS, 2007.

Viva o Charque. Obelisco. Disponível em: http://www.vivaocharque.com.br/cenarios/obelisco.php. Acessado em 11 de junho de 2013.

Recebido em: 09/06/2015 Aceito em: 08/11/2015 